\title{
Bromodeoxyuridine in Tumors and Chromosomes \\ Detected with a Monoclonal Antibody
}

\author{
G. Morstyn, S.-M. Hsu, T. Kinsella, H. Gratzner, A. Russo, and \\ J. B. Mitchell, Radiation Oncology Branch, Division of Cancer Treatment \\ and Laboratory of Pathology, Division of Cancer Biology and Diagnosis, \\ National Cancer Institute, Bethesda, Maryland 20205; Institute for \\ Cell Analysis, University of Miami Hospitals and Clinics, \\ National Children's Hospital, Miami, Florida 33101
}

\begin{abstract}
A B S T R A C T Using a monoclonal antibody to bromodeoxyuridine (BUdR) and immunohistochemistry, we measured the incorporation of this thymidine analogue into the DNA of human normal and malignant cells exposed in vivo. BUdR given as a constant intravenous infusion for 12 or $24 \mathrm{~h}$ daily for up to $13 \mathrm{~d}$ resulted in a steady-state plasma level of $10^{-6} \mathrm{M}$ during the infusion. We demonstrated extensive incorporation of BUdR into both normal skin, normal bone marrow, and malignant melanoma cells. In addition, this infusion of BUdR was adequate to identify sister chromatid exchanges from human marrow chromosomes exposed in vivo. Using this constant infusion, significant but reversible (acute) toxicity was observed with myelosuppression and skin photosensitivity. These techniques, which are considerably less cumbersome and time-consuming than the use of radioactive isotopes of thymidine, can be used for further human studies of cell kinetics and chromosomal replication in both normal and malignant cells.
\end{abstract}

\section{INTRODUCTION}

Studies of cell cycle kinetics and of nucleotide incorporation into the DNA of various tissues are important for understanding normal and malignant cell growth (1). Tritiated thymidine incorporation into DNA de-

Address all correspondence to Dr. James B. Mitchell, Radiation Oncology Branch, National Cancer Institute, Bldg. 10, Rm. B3B69, Bethesda, MD 20205.

Received for publication 20 June 1983 and in revised form 5 August 1983. tected by autoradiography has been used to study the cell kinetics of normal and malignant cells in vivo and in vitro $(1,2)$. Bromodeoxyuridine (BUdR), ${ }^{1}$ a pyrimidine analogue of thymidine, produces significant $x$ ray sensitization following incorporation into DNA (3). Clinical trials using BUdR showed enhanced $x$-ray sensitivity of human tumors (4-5); however, it has not been possible to directly demonstrate BUdR incorporation into normal or malignant cells. As part of a clinical investigation evaluating BUdR as an in vivo $x$-ray sensitizer (5), we used a monoclonal antibody and immunohistochemistry to measure BUdR incorporation into the DNA of normal and malignant cells. This technique could quantitate the proportion of normal and malignant cells incorporating BUdR during the period of infusion and, therefore, the proportion of cells dividing (i.e., labeling index). This immunohistochemical technique was also used to detect BUdR in the chromosomes of marrow cells and for the first time directly demonstrate the phenomenon of sister chromatid exchange (SCE) (6) in man in vivo.

\section{METHODS}

\section{Therapy of patients and procurement of human specimens}

Tumor and normal tissue specimens were obtained from patients treated with BUdR in a study at the National Cancer Institute. Written informed consent was obtained before

\footnotetext{
${ }^{1}$ Abbreviations used in this paper: BUdR, bromodeoxyuridine; SCE, sister chromatid exchanges.
} 
entry in the study. One patient with malignant melanoma was treated with BUdR $650 \mathrm{mg} / \mathrm{m}^{2}$ by continuous in vivo infusion for $8 \mathrm{~d}$. Skin, tumor, and marrow biopsies were obtained before and after the 8 -d infusion. The second patient, also with malignant melanoma, was treated with BUdR $650 \mathrm{mg} / \mathrm{m}^{2}$ by intravenous infusion for $12 \mathrm{~h}$ every $24 \mathrm{~h}$ for $13 \mathrm{~d}$. He received local radiotherapy for the last $7 \mathrm{~d}$. A punch biopsy of the melanoma was obtained following the 13-d infusion.

\section{Flow cytometric analysis of BUdR incorporation}

Chinese hamster V79 cells in log phase growth were cultured in F12 medium supplemented with $10 \%$ fetal calf serum. The cells were exposed to BUdR at a concentration of $10^{-5}$ or $10^{-6} \mathrm{M}$ for $17 \mathrm{~h}$ (approximately two cell cycles); control cells were not treated with BUdR. The cells were harvested by trypsinization and washed two times in $0.1 \mathrm{M}$ phosphate-buffered saline (PBS). The cell pellet was fixed in $50 \%$ ethanol at $4^{\circ} \mathrm{C}$ for $2 \mathrm{~h}$. The cells were then treated with $1 \mathrm{~N} \mathrm{HCl}$ for $10 \mathrm{~min}$, centrifuged, and resuspended at $5 \times$ $10^{6}$ cells $/ \mathrm{ml}$ in $0.2 \mathrm{ml}$ PBS with $10 \%$ goat serum. A monoclonal antibody directed against BUdR was prepared as previously described (7). This antibody was used at a dilution of $1: 20$ to stain the cells $(60 \mathrm{~min}$ at room temperature). The cells were washed two times in PBS with $10 \%$ goat serum, then stained with an affinity-purified fluorescein-conjugated goat anti-mouse IgG second antibody (Cappel Laboratories, Inc., Cochranville, PA) for $1 \mathrm{~h}$. The cells were analyzed on a fluorescence-activated cell sorter (FACS II, Becton, Dickinson \& Co., Mountain View, CA) by using the 488-nm line of an argon ion laser at $500 \mathrm{~mW}$ power. Data analysis was based on the collection of 10,000-50,000 cells/sample.

\section{Immunohistochemical staining of incorporated BUdR}

V79 cells. Microscope slide preparations were made of V79 cells that had incorporated BUdR $\left(10^{-6}\right.$ or $10^{-5} \mathrm{M}$ for $17 \mathrm{~h}$ ) or no BUdR. The cells were fixed in acetone, treated with $0.1 \mathrm{~N} \mathrm{HCl}$, stained with the anti-BUdR monoclonal antibody (dilution 1:40), washed, stained with a biotin-conjugated horse anti-mouse antibody (Vector Laboratories, Inc., Burlingame, CA, at a dilution of 1:200), and stained with an avidin-biotin-peroxidase complex (8). Visualization of the reaction product was achieved with the diaminobenzidine$\mathrm{H}_{2} \mathrm{O}_{2}$ reaction as previously described (8). Cells that contained BUdR were identified by the presence of a dark pigment over their nuclei.

Normal and malignant human tissue. Biopsies of normal skin and two malignant melanomas were obtained before and after treatment; frozen sections were prepared and stained as described above or with hematoxylin and eosin.

Incorporation of BUdR into chromosomes. Marrow cells from patients receiving BUdR infusions were incubated in $0.5 \mu \mathrm{g} / \mathrm{ml}$ of colchicine for $1 \mathrm{~h}$, followed by treatment with hypotonic PBS $(0.02 \mathrm{M})$ and fixation in methanol and acetic acid (3:1). The chromosomes were treated with $0.1 \mathrm{~N}$ hydrochloric acid and allowed to air-dry. The slides were then stained with the monoclonal anti-BUdR antibody and the immunohistochemical procedure described previously. 25 metaphase chromosomes were examined from one patient. In a parallel study, chromosomes were also stained with a technique used previously to identify BUdR incorporation into chromosomes in vitro and based on differential chromatid staining following exposure to Hoechst 33258 and Giemsa (9).

\section{Measurement of blood levels of BUdR}

Blood levels were assayed using a high-performance liquid chromatography technique (manuscript submitted for publication).

\section{RESULTS}

BUdR incorporation into V79 cells. As a preliminary study to test the feasibility of this technique, Chinese hamster ovary V79 cells were cultured in $10^{-5}$ or $10^{-6} \mathrm{M}$ BUdR or no BUdR for $17 \mathrm{~h}$. BUdR was detected in these cells both by a fluorescent antibody technique (Fig. $1 A$ ) and by immunohistochemical staining (Fig. $1 B-D$ ), following as little as $17 \mathrm{~h}$ of exposure. The ordinate in Fig. 1 shows the relative cell number and the abscissa the relative fluorescence intensity (divided into 1,000 logarithmic channels) of cells stained with the monoclonal antibody anti-BUdR and a second fluorescein-conjugated goat anti-mouse IgG antibody. The cells exposed to BUdR were clearly more fluorescent and the cells that had been exposed to the higher concentration of BUdR yet even more fluorescent. The median fluorescence channel for cells incubated in $10^{-5} \mathrm{M}$ BUdR was 647 , for $10^{-6} \mathrm{M}$ it was 601 , and for cells that had not incorporated BUdR it was 456. Examination of the cells by fluorescence microscopy confirmed that fluorescence was localized in the nucleus and a study with ${ }^{3} \mathrm{H}$-labeled BUdR (data not shown) confirmed that cells exposed to the higher concentration of BUdR incorporated more BUdR. Panels $B-D$ show the cells stained with the immunohistochemical technique; panel $B$, cells incubated in the presence of $10^{-5} \mathrm{M}$ BUdR; panel $C$, cells incubated in the presence of $10^{-6} \mathrm{M}$ BUdR; and panel $D$, no BUdR. Cells that incorporated BUdR were darkly stained over the nucleus and there was clearly more staining of cells incubated in the higher concentration of BUdR and no staining of cells not exposed to BUdR (panel $D$ ). These studies established that the immunohistochemical technique quantitatively detected BUdR incorporation into DNA.

BUdR incorporation into human cells. Tumor and normal tissue specimens were obtained from patients treated with BUdR as a radiosensitizer in a study at the National Cancer Institute. One patient (Fig. 2) was exposed to a constant blood level of BUdR for $8 \mathrm{~d}$. A marrow biopsy was obtained and chromosome preparations were made. The chromosomes were stained with the immunohistochemical technique (Fig. 2). Chromosomes in 25/25 metaphases had darkly stained chromatids, therefore suggesting they had incorporated BUdR. There was no background staining with the 

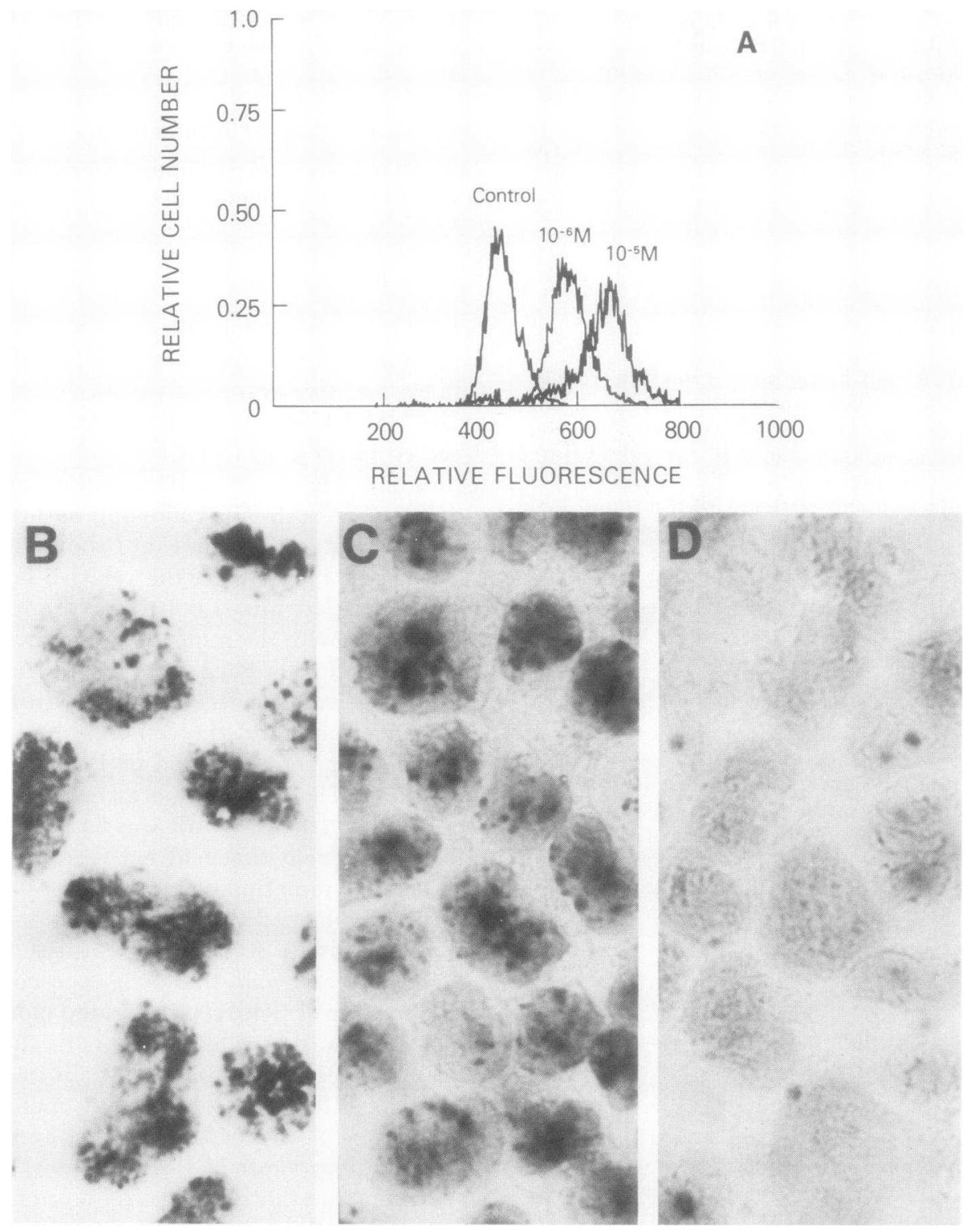

Figure 1 (A) Chinese hamster V79 cells in log phase growth were exposed to BUdR at $10^{-5}$ or $10^{-6} \mathrm{M}$ for $17 \mathrm{~h}$. They were stained with a monoclonal anti-BUdR antibody and a fluoresceinconjugated goat anti-mouse second antibody. The plot shows the relative cell number vs. fluorescence intensity. Cytospin preparations were also made of the V79 cells that had incorporated BUdR $\left(10^{-5} \mathrm{M}\right.$, panel $B$, or $10^{-6} \mathrm{M}$, panel $C$, for $17 \mathrm{~h}$ ) or no BUdR (panel $D$ ). The cells were stained with the anti-BUdR antibody (dilution 1:20), a biotin-labeled horse anti-mouse antibody, and an avidin-biotin-peroxidase complex. Visualization of the reaction product was achieved with diaminobenzidine $-\mathrm{H}_{2} \mathrm{O}_{2}$ reaction.

second antibody alone and chromosomes obtained from cells before therapy with BUdR did not bind the antibody and therefore did not stain. Several of the chromosomes displayed differential chromatid staining (Fig. 2 ), indicating that the antibody bound more to chromatids with two DNA strands containing BUdR than those with one. This staining pattern identifies this cell as a second division metaphase that had incorporated BUdR for two rounds of DNA synthesis. The arrows indicate portions of chromatids where SCE occurred in vivo. The appearance was similar to that observed when chromosomes from human lymphocytes are exposed to BUdR in vitro and stained using the Hoechst stain 33258 and Giemsa. A parellel study using the 


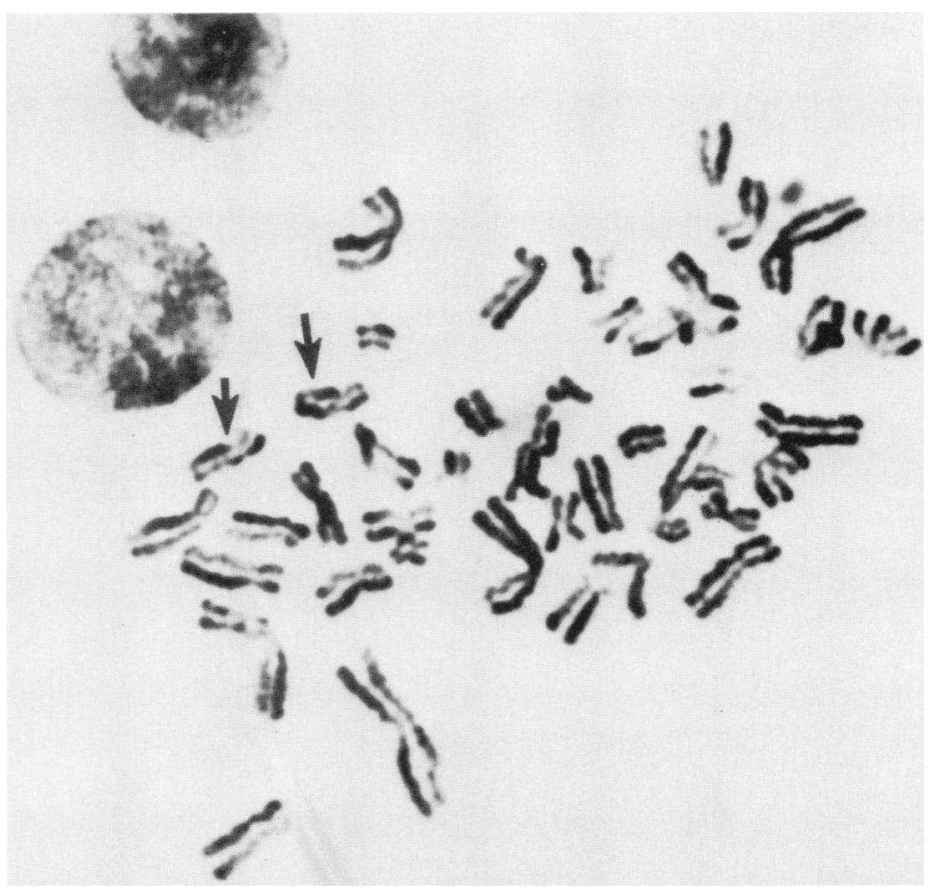

FIGURE 2 A chromosome preparation stained with the immunohistochemical technique from the marrow of a patient treated with BUdR. The staining pattern observed establishes that this cell is a second division (with BUdR incorporation) metaphase. The arrows indicate SCE.

Hoechst stain and Giemsa technique to stain the chromosomes from the same patient also demonstrated differential chromatid staining, confirming the presence of BUdR in these chromosomes (data not shown).

The immunohistochemical staining method (Fig. 3) revealed that after in vivo infusion, BUdR was present in the nuclei of $10-50 \%$ of human malignant cells and in the basal layer of cells of the normal epidermis. Biopsies from two malignant melanomas were obtained before and after in vivo exposure to blood levels of $1-2 \times 10^{-6} \mathrm{M}$ BUdR for 8 (Fig. $3 \mathrm{~A}-\mathrm{C}$ ) and 13 (Fig. $3 D-F)$ d. Frozen sections were stained as described or with hematoxylin and eosin. The first tumor consisted of small nodules $\left(0.5 \mathrm{~cm}^{3}\right.$ in size $)$. There was no staining of any cells in the tissue biopsies obtained before treatment with BUdR (Fig. 3, panel A). Panel $B$ is a low-power view of the skin and tumor following biopsy. Dark staining over the nuclei of the cells indicates BUdR incorporation into the DNA of these cells. Incorporation of BUdR was relatively homogeneous, and of 1,000 cells examined, $10 \%$ had incorporated BUdR during the $8 \mathrm{~d}$ of infusion. The staining was specific since no staining was detected when the first antibody was replaced with MOPC mouse myeloma protein, pooled mouse immunoglobulin, or mouse ascites fluid from NS-1.

Panels $D, E$, and $F$ show tissue sections from the second patient, who had a large rapidly growing malignant melanoma $30 \times 30 \times 34 \mathrm{~cm}$ in size and was treated with $650 \mathrm{mg} / \mathrm{m}^{2}$ of BUdR by intravenous infusion for $12 \mathrm{~h}$ every $24 \mathrm{~h}$ for $13 \mathrm{~d}$. He received radiotherapy for the last $7 \mathrm{~d}$. The blood levels of BUdR were $2 \times 10^{-6} \mathrm{M}$ during the $12 \mathrm{~h}$ of drug infusion and rapidly dropped when the infusion was stopped. The leukocyte count remained constant during therapy but the platelet count fell from 557,000 to $125,000 / \mathrm{mm}^{3}$. A punch biopsy of the melanoma after the 13-d infusion was frozen in liquid nitrogen, tissue sections were prepared and then stained with the immunohistochemical technique. There was very little background staining (Fig. 3, panel $D$ ) but strong staining of the nuclei in the tumor and in the normal epidermis (panels $E$ and $F$ ). There was heterogeneity in the proportion of cells containing BUdR in different portions of this tumor. Panel $F$ of Fig. 3 shows a portion of the tumor where few of the nuclei appear to have incorporated BUdR, surrounded by an area in which a large proportion of the cells appear to contain BUdR.

\section{DISCUSSION}

We have developed an immunohistochemical technique to identify BUdR in the nuclei of cells while preserving the tissue structure. A monoclonal antibody to BUdR 


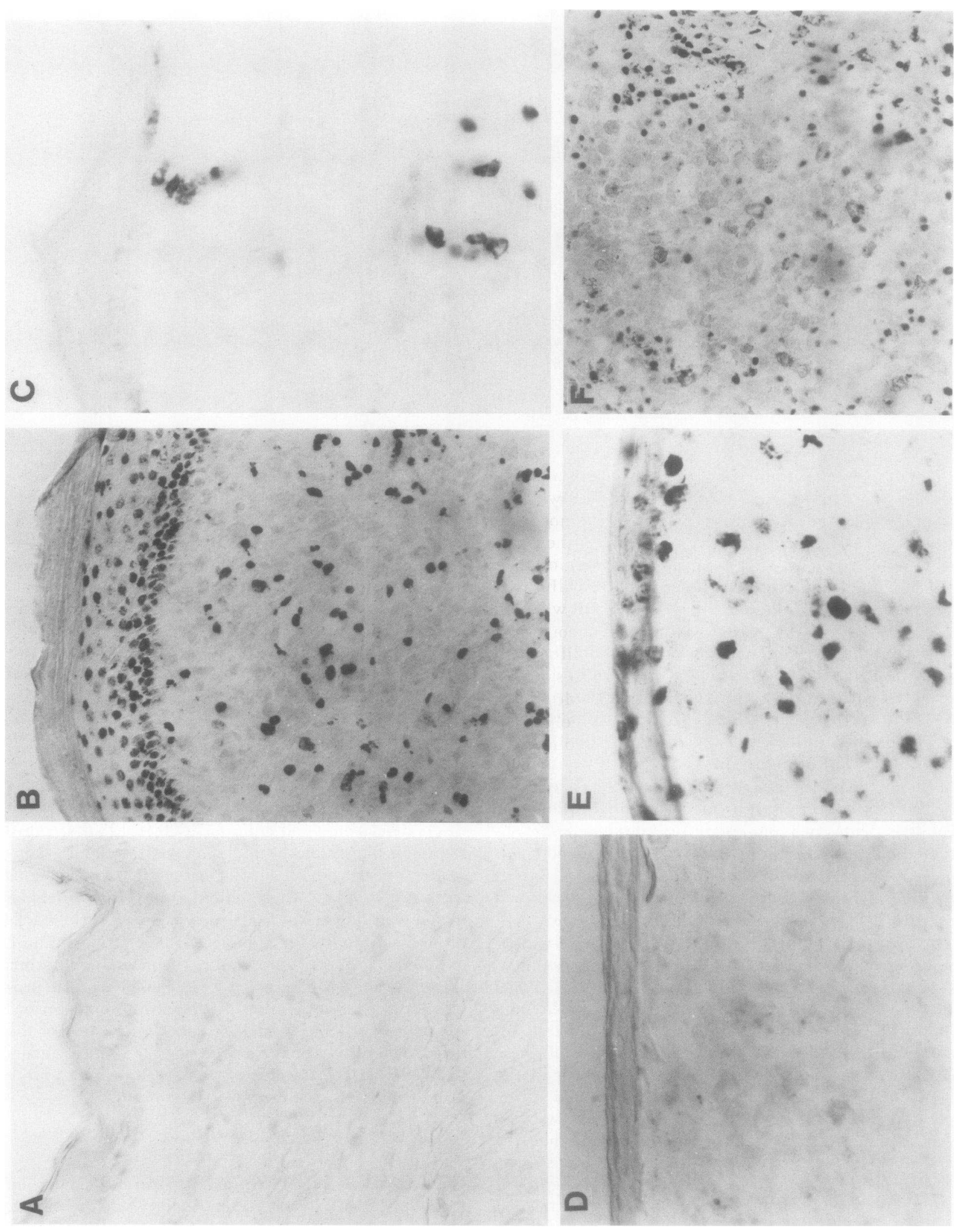


was found to bind to cell nuclei containing BUdR. This was demonstrated using both a fluorescence technique and the immunohistochemical technique.

This immunohistochemical technique was then used to identify BUdR in tissue biopsies obtained before and after therapy. As expected, it was found that BUdR had been extensively incorporated into both malignant and normal cells following in vivo administration. Distribution of cells that had incorporated BUdR was relatively uniform in the small malignant melanoma nodules examined. However, the distribution of cells that had incorporated BUdR in the large melanoma was more heterogeneous, with $10-50 \%$ of the cells containing BUdR in different portions of the tumor. Variation in the labeling of this tumor was consistent with previous findings using $\left[{ }^{3} \mathrm{H}\right]$ thymidine in vivo in large tumor masses (2). The variability of proliferation in different portions of the tumor may be due to differences in perfusion.

The finding of large portions of the tumor with no BUdR suggests that only some of the cells in a tumor can be sensitized to radiation by BUdR. BUdR was also found in normal cells, confirming that it is not a selective radiosensitizer for malignant cells, although it is possible the extent of sensitization of tumor cells may be greater if they incorporate more BUdR.

In skin, the greatest incorporation of BUdR was seen in the basal layer of the epidermis, which is consistent with this being the site of highest cell proliferation. There was also significant incorporation into skin adnexal structures, such as sebaceous glands. More proliferation was seen in the normal epidermal cells overlying the tumor than in epidermal cells from other sites.

The incorporation of BUdR into normal skin and into the normal proliferating cells in the marrow demonstrated directly in this study for the first time is not surprising. In addition to $x$-rays, BUdR also sensitizes cells to UV light (10) and to fluorescent light (unpublished observations) and so its presence in the normal epidermis is consistent with the skin phototoxicity observed when patients are treated with BUdR. BUdR is cytotoxic at high concentrations (3) and therefore the incorporation of BUdR into normal cells in the bone marrow probably produces the fall in blood counts often observed and the enhanced radiation sensitivity of marrow progenitor cells (11). The mechanism(s) by which BUdR sensitizes cells to UV light and causes cytotoxicity are not totally understood. It has been shown that photoproducts resulting from bromine radicals, as well as uracil radicals, transiently exist (12). The injury from these products can result in both singleand double-strain breaks in DNA (12). The etiology of cytotoxicity resulting from substitution of thymidine by BUdR may result from interference with the function of DNA (13).

BUdR in chromosomes in the marrow after in vivo infusion allowed us to demonstrate for the first time that in man SCE occur in vivo. In vivo SCE has previously been reported using animal systems $(14,15)$. Although the significance between SCE elevation and exposure to a variety of mutagens is uncertain, there appears to be a relationship (16). Our method should allow for the study of in vivo SCE induction following chemotherapeutic agents (that are also mutagens) in selected patients.

There are several advantages to the technique we described over those of $\left[{ }^{3} \mathrm{H}\right]$ thymidine for in vivo cell kinetic studies in man. Since most studies of this nature have been conducted in a clinical setting, the use of $\left[{ }^{3} \mathrm{H}\right]$ thymidine for cell kinetic studies has involved exposure to a potentially hazardous radioactive compound in addition to the prescribed therapy. In our study, BUdR itself is a major part of the therapy and therefore cell kinetic studies can be conducted without introducing additional procedures. Although we have found significant but readily reversible toxicity to bone marrow and skin using a prolonged infusion (5), it is quite possible that important kinetic information can be obtained with a shorter, less toxic infusion. Studies are planned with infusion periods for only 1-2 d. Although BUdR is a known mutagen (17), a short infusion in selected patient populations may allow for in vivo studies of chromosome replication and cell kinetics in a variety of chronic diseases. Secondly, in vivo $\left[{ }^{3} \mathrm{H}\right]$ thymidine studies in man are cumbersome, timeconsuming (up to months for autoradiograph storage), and, due to low levels of isotope incorporation, the interpretation of autoradiographs can often times be difficult. The BUdR technique we describe is rapid and easily interpreted with a minimum of background staining. The recently renewed clinical interest in BUdR as an $x$-ray sensitizer (5) provides a good opportunity to reexamine human malignant and normal cell kinetics in vivo. Our approach, based on the detection of BUdR by immunohistochemistry, may have

Figure 3 Biopsies of malignant melanomas and skin from two patients stained with an immunohistochemical technique. Panels $A, B$, and $C$ show biopsies from the first patient's melanoma and from uninvolved skin (panel $A$ : pre-BUdR, panels $B$ and $C$ : post-BUdR). Panels $D$, $E$, and $F$ are biopsies from the second patient's melanoma (panel $D$ : second antibody control; panels $E$ and $F$ : first and second antibody). 
many applications, and, in some studies, replace $\left[{ }^{3} \mathrm{H}\right]$ thymidine detected by autoradiography.

\section{ACKNOWLEDGMENTS}

We thank L. Neckers for providing the cell sorter, C. S. Shan for a chromosome preparation, M. Aiken for technical assistance, and M. Singleton for production of the manuscript.

\section{REFERENCES}

1. Tubiana, M., and E. P. Malaise. 1977. Growth rate and cell kinetics in human tumours: some prognostic and therapeutic implications. In Scientific Foundations of Oncology. T. Symington and R. L. Carter, editors. William Heinemann, Ldt., London.

2. Shirakawa, S., J. K. Luch, I. Tannock, and E. Frei. 1970. Cell proliferation in human melanoma. J. Clin. Invest. 49:1188-1199.

3. Szybalski, W. 1974. X-ray sensitization by halopyrimidines. Cancer Chemother. Rep. 58:539-557.

4. Bagshaw, M. A., R. L. S. Doggett, K. C. Smith, H. S. Kaplan, and T. S. Nelsen. 1967. Intra-arterial 5-bromodeoxyuridine and x-ray therapy. Radiology. 99:886894.

5. Kinsella, T. J., A. Russo, J. B. Mitchell, J. Rowland, J. Jenkins, J. Schwade, C. E. Meyers, J. M. Collins, J. Speyer, P. Kornblith, B. Smith, C. Kufta, and E. Glatstein. 1983. A phase I study of intermittent intravenous BUdR with conventional irradiation. Int. J. Radiat. Oncol. Biol. Phys. In press.

6. Latt, S. A. 1973. Microfluorometric detection of deoxyribonucleic acid replication in human metaphase chromosomes. Proc. Natl. Acad. Sci. USA. 70:3395-3399.

7. Gratzner, H. G. 1982. Monoclonal antibody to 5-bromo- and 5-iododeoxyuridine: a new reagent for detection of DNA replication. Science (Wash. DC). 218:474-475.

8. Hsu, S.-M., J. Cossman, and E. S. Jaffe. 1983. Lymphocyte subsets in normal human lymphoid tissues. Am. J. Clin. Pathol. 80:21-30.

9. Goto, K., S. Maeda, Y. Kano, and T. Sugigama. 1978 Factors involved in differential Giemsa staining of sister chromatids. Chromosoma (Berl.). 66:351-359.

10. Hagan, M. P., and M. M. Elkind. 1979. Changes in repair competency after 5-bromodeoxyuridine pulse labeling and near ultraviolet light. Biophys. J. 27:75-85.

11. Mitchell, J., T. J. Kinsella, A. Russo, S. McPherson, J. Rowland, P. Kornblith, and E. Glatstein. 1983. Radiosensitization of hematopoietic precursor cells (CFUc) in glioblastoma patients receiving intermittent intravenous infusions of bromodeoxyuridine (BUdR). Int. J. Radiat. Oncol. Biol. Phys. 9:457-463.

12. Hutchinson, F. 1973. The lesions produced by ultraviolet light in DNA containing 5-bromouracil. Q. Rev. Biophys. 6:201-246.

13. Littlefield, J. W., and E. A. Gould. 1960. Toxic effects of 5-bromodeoxyuridine on cultured epithelial cells. $J$. Biol. Chem. 235:1129-1133.

14. Vogel, W., and T. Bauknecht. 1976. Differential chromatid staining by in vivo treatment as a mutagenicity test system. Nature (Lond.). 260:448-449.

15. Allen, J. W., and S. A. Latt. 1976. Analysis of sister chromatid exchange formation in vivo in mouse environmental mutagens. Nature (Lond.). 260:449-451.

16. Perry, P., and H. J. Evans. 1975. Cytological detection of mutagen-carcinogen exposure by sister chromatid exchange. Nature (Lond.). 258:121-125.

17. Barrett, J. C., T. Tsutsui, and P. O. P. Ts'o. 1978. Neoplastic transformation induced by a direct perturbation of DNA. Nature (Lond.). 274:229-232. 